IZA DP No. 7814

Transitions in Labour Market Status in the EU

Melanie Ward-Warmedinger

Corrado Macchiarelli

December 2013

Forschungsinstitut zur Zukunft der Arbeit Institute for the Study of Labor 


\title{
Transitions in Labour Market Status in the EU
}

\author{
Melanie Ward-Warmedinger \\ European Central Bank \\ and IZA
}

Corrado Macchiarelli

London School of Economics

\section{Discussion Paper No. 7814 \\ December 2013}

\author{
IZA \\ P.O. Box 7240 \\ 53072 Bonn \\ Germany \\ Phone: +49-228-3894-0 \\ Fax: +49-228-3894-180 \\ E-mail: iza@iza.org
}

Any opinions expressed here are those of the author(s) and not those of IZA. Research published in this series may include views on policy, but the institute itself takes no institutional policy positions. The IZA research network is committed to the IZA Guiding Principles of Research Integrity.

The Institute for the Study of Labor (IZA) in Bonn is a local and virtual international research center and a place of communication between science, politics and business. IZA is an independent nonprofit organization supported by Deutsche Post Foundation. The center is associated with the University of Bonn and offers a stimulating research environment through its international network, workshops and conferences, data service, project support, research visits and doctoral program. IZA engages in (i) original and internationally competitive research in all fields of labor economics, (ii) development of policy concepts, and (iii) dissemination of research results and concepts to the interested public.

IZA Discussion Papers often represent preliminary work and are circulated to encourage discussion. Citation of such a paper should account for its provisional character. A revised version may be available directly from the author. 


\section{ABSTRACT}

\section{Transitions in Labour Market Status in the EU ${ }^{1}$}

This paper presents information on labour market mobility in 23 EU countries, using Eurostat's Labour Force Survey (LFS) data over the period 1998-2008. More specifically, it discusses alternative measures of labour market churning; including the ease with which individuals can move between employment, unemployment and inactivity over time. The results suggest that the probability of remaining in the same labour market status between two consecutive periods is high for all countries. Nonetheless, transitions from unemployment and inactivity back into the labour market are relatively weak in the euro area and central eastern European EU (CEE EU) countries compared to Denmark and, particularly, Sweden. Moreover, comparisons of transition probabilities over time suggest that - until the onset of the financial crisis - the probability of remaining in unemployment over two consecutive periods decreased in Sweden, the euro area, and, to a lesser extent, Denmark, while it increased in the average CEE EU countries. At the same time, however, successful labour market entries (from outside the labour market) increased in the average CEE EU countries, Denmark and Sweden. On the basis of an index for labour markets turnover used in the paper (Shorrocks, 1987), labour markets in Spain, Luxemburg, the Netherlands, Denmark and Sweden are the most mobile on average, with these results mainly reflecting higher mobility of people below the age of 29 , highly educated and female workers. We also find that mobility of all worker groups has generally increased over time in the euro area, Denmark and Sweden. Finally, we ask whether some of the observed changes in mobility can be broadly restraint to some "macro" explanatory factors, including part time and temporary employment, unemployment and structure indicators. The results provide a mixed picture, suggesting that the sense of mobility strongly varies across countries.

JEL Classification: J21, J60, J82, E24

Keywords: $\quad$ transition probabilities, labour market mobility, LFS micro data, EU countries

Corresponding author:

Corrado Macchiarelli

London School of Economics and Political Science

Houghton Street

WC2A 2AE London

United Kingdom

E-mail: c.macchiarelli@Ise.ac.uk

\footnotetext{
${ }^{1}$ The views expressed are those of the authors only and should not be reported as representing the views of the European Central Bank (ECB). The authors are grateful to Julian Morgan, Giulio Nicoletti, José Marín Arcas and other participants at an internal seminar organized by the Directorate Economic Developments of the ECB. The paper also benefited from comments provided by participants at an internal seminar organized by the Centre for European Economic Research (ZEW). Finally, the authors are thankful to Vassilis Monastiriotis for further input and discussion.
} 


\section{INTRODUCTION}

This paper utilises the available microeconomic data behind the Eurostat's Labour Force Survey (LFS) to present alternative measures of labour market mobility across EU countries over time, and in particular the ease of transition between the labour market statuses of unemployment, employment and out of the labour market (inactivity) over the period 1998-2008. ${ }^{2}$ As well as identifying stylized facts, the aim of this paper is to shed some light on the functioning of the EU labour markets.

Until the onset of the crisis, the EU experienced a reduction in unemployment rate, essentially driven by a fall in long term unemployment and unemployment duration (Table 1). ${ }^{3}$ A quick look at the standardized unemployment (employment) rates by country confirms that most EU countries were successful in reducing (improving) unemployment (employment) before the crisis. However, across the EU, unemployment (employment) rates behaved very differently, with some countries displaying steadily declining (increasing) unemployment (employment) rates over time, while others exhibiting more marked unemployment (employment) fluctuations; i.e. with unemployment (employment) increasing (decreasing) after the 2001-02 global recession and - in many central eastern European EU (CEE EU) countries - raising (waning) following the 1998 Russia crisis, before declining again (improving) in the light of EU membership (see also Epstein and Macchiarelli, 2010; Macchiarelli, 2013a; b).

Alongside the macroeconomic picture of a decrease in unemployment rate and duration, the use of micro data can help assess if such developments at the EU level reflected an increase in the number of people transitioning from unemployment to employment, or, on the contrary, an increase in the transitions from unemployment to inactivity. Similarly, microeconomic data can help highlight whether the increase in the employment rate resulted from an

\footnotetext{
2 The anonymized version of this data (which is used in this analysis and is the only version for many countries currently available to the ECB) suffers from some limitations in its use for economic analysis since individuals cannot be tracked over time and there are significant changes in the information collected, variable definitions and coding which limit the time series dimension of the data.

${ }^{3}$ A decrease in the average unemployment duration from 18 months (1998) to 11 months (2008) can be overall observed in Europe (Table 1).
} 
increase in employment persistence (more people remaining in employment), an increase in transitions from unemployment to employment, or an increase in transitions from inactivity to employment. Finally, the use of microeconomic data also allows for the construction of measures of the degree of labour market flexibility, and how this varied across countries and over time. The analysis of transitions into and out of unemployment thus offers significant advantages over an analysis of macroeconomic developments, allowing us to observe the directions of flows and levels of status mobility behind any particular change in the aggregate employment, unemployment or inactivity rate. Moreover, the proposed methodology allows quantitatively assessing the role played by labour market flows, by readily analysing how mobility measures evolved over time and across worker groups (gender, age and education).

The contribution of the paper can be gauged under two perspectives. First, we provide results for a large set of countries, by providing a systematic, unconditional approach to estimate labour market transitions in most EU countries. Secondly, we exploit cross country differences in the size and the speed with which labour market changes took place over time.

In our analysis, a number of stylized facts are documented. First, we find that the probability of remaining in the same labour market status between two consecutive periods is high for all countries. Nonetheless, transitions from unemployment and inactivity back into the labour market are relatively weak in the euro area and central eastern European EU (CEE EU) countries compared to Denmark and, particularly, Sweden. Secondly, comparisons of transition probabilities over time suggest that - until the onset of the financial crisis - the probability of remaining in unemployment over two consecutive periods decreased in Sweden and in the euro area, while it increased in the average CEE EU countries. At the same time, however, successful labour market entries (from outside the labour market) increased in CEE EU countries, Denmark and Sweden.

Finally, on the basis of an index for labour markets turnover used in the paper (Shorrocks, 1987), labour markets in Spain, Luxemburg, the Netherlands, Denmark and Sweden are the most mobile on average, with these results mainly 
reflecting higher mobility of people below the age of 29, highly educated and female workers. We also find that mobility of all worker groups has generally increased over time in the euro area, Denmark and Sweden.

In the last section, we look at the link between macroeconomic developments and changes in mobility indexes. The results suggest that countries who experienced an increase in mobility are also those which increased their percentage of time limited (e.g., temporary) contracts and part time work, and viceversa. However, looking at unemployment rates and some structure indicators the results provide a mixed picture, suggesting that the sense of mobility and its implications strongly vary across countries.

The remainder of the paper is organized as follows. Section 2 presents the methodology and our main results. Section 3 looks at some explanatory factors behind the observed labour market mobility in each country. Section 4 concludes.

\section{LABOUR MARKET TRANSITIONS}

\subsection{Transitions in labour status in the EU}

A number of papers have focused on establishing the persistence of both unemployment incidence and duration using longitudinal data with a relatively short time horizon (Boeri and Garibaldi, 2009; Petrongolo and Pissarides, 2008; Brandolini et al., 2006 for Europe; Vanhala, 2009; Elsby et al., 2009 for OECD countries). ${ }^{4}$ These papers document an increase in status mobility during the last two decades, with differences in the extent of mobility across countries being attributed to institutional factors. Boeri and Garibaldi (2009) ask, for instance, why the decrease in unemployment does not show up as increased satisfaction in the labour market, a result they attribute to the increased risk of job loss that higher mobility implies. Elsby et al. (2009) instead question the validity of the assumption of a steady state decomposition for unemployment

\footnotetext{
${ }^{4}$ See, inter alia, Fujita and Ramey (2006); Shimer (2007) for the US.
} 
which forms the basis of a number of theoretical models. Petrongolo and Pissarides (2008) identify the relative role of inflow and outflow rate from unemployment in explaining labour market dynamics and conclude that the relative contribution of each depends on labour market institutions. In the same vein, Vanhala (2009) argues that European countries generally have low unemployment inflow and outflows rates which contribute to high rates and unemployment persistence. Brandolini et al. (2006) emphasise the need to acknowledge the group of non-participants (or potentially unemployed) when looking at labour market dynamics; accordingly the distinction provided for by the ILO definition of unemployment is only "artificial" and indeed nonparticipants and unemployed do not differ substantially in their job search activity.

We use gross data flows from the Eurostat's Labour Force Survey (LFS) microdata for 23 countries. The UK, Germany (DE), Malta (MT) and Ireland (IE) are excluded from the analysis owing to a lack of data. ${ }^{5}$ The remaining countries are grouped as follows:

- Euro area countries, including EMU members until 2008, i.e. Spain (ES), Italy (IT), France (FR), the Netherlands (NL), Belgium (BE), Austria (AT), Cyprus (CY), Finland (FI), Greece (GR), Luxemburg (LU), Portugal $(\mathrm{PT})$, Slovenia $(\mathrm{SI})$.

- Central Eastern EU non euro area countries (hereafter, CEE EU), including Czech Republic (CZ), Estonia (EE), Latvia (LV), Lithuania (LT), Hungary (HU), Poland (PL), Romania (RO) and Slovakia (SK).

- Denmark (DK) and Sweden (SE).

We use a relatively comprehensive sample which focuses on the period between 1998 and 2008. Stopping the sample in 2008 is motivated by the idea that EU labour markets sensitively lagged the slack in the real activity, showing a worsening of unemployment figures mainly starting from 2009. Hence, with the

\footnotetext{
${ }^{5}$ Due to missing data, some countries are also excluded when computing aggregated results for the euro area or the CEE EU. Based on the LFS, data are not available for Germany on the overall sample, for Spain prior to 2006, for France for the 2003-2005 period, for Luxemburg and Slovenia prior to 1999 and 2000 respectively. For the Netherlands data availability reduces to 2008 for transitions from unemployment, and to 2006-2008 for transitions from employment and inactivity. For Latvia, Lithuania and Slovakia data are missing prior to 2001, for Romania and Hungary prior to 1999. For Sweden data are missing in 2005.
} 
purpose of identifying stylized labour market facts, the crisis and ensuing labour adjustments are for now excluded.

\section{[Table 1 approximately here]}

Eurostat Labour Force Survey Statistics are available in yearly frequencies and are constructed from a rotating panel reporting information based on anonymous interviews. The LFS microdata dataset provides the longest time series of comparable and consistently defined individual level data that is available for the EU, and our sample consists of individuals between the ages of 16 and 64 .

Year-on-year transitions are obtained based on the subjective assessment of the respondent's current and past working situation. ${ }^{6}$ In this way, the labour market status in the initial ( $\mathrm{t}-1)$ and the final period $(\mathrm{t})$ is the subjective assessment of the respondent's current and past working status, reported at the time of the survey $(\mathrm{t})$.

Using data from subjective classifications prompt several methodological questions. First, whether subjective classifications capture actual levels of labour market turnovers, or they capture, in fact, the behaviour of individuals potentially moving across labour market statuses (see Brandolini et al., 2006). ${ }^{3}$ Secondly, retrospective data can go wrong as people can forget, make mistakes or simply do not respond, naturally giving rise to spurious changes in statuses. Third, period-censoring (or, collecting answers referring to the survey year and the year before) does not allow capturing flows between survey dates. ${ }^{7}$

\footnotetext{
${ }^{6}$ The LFS questionnaire asks about (i) the individual's socio-economic situation one year before the survey date and (ii) their current professional status during the reference week (i.e. in period $t$ ). Our measure is therefore an 'annual' transition measure and presents a lower bound for labour market mobility. No information is available about labour market mobility within a particular year. In addition, a similar analysis using objective classifications for each labour market state (i.e. ILO definitions) is not feasible, owing to a lack of data. For further details see http://circa.europa.eu/irc/dsis/employment/info/data/eu_lfs.

${ }^{7}$ The latter limitation - common to such kind of studies (Boeri and Flinn, 1999; Boeri and Garibaldi, 2009) - allows only observing labour market flows between the survey date $(\mathrm{t})$ and the year before $(\mathrm{t}-1)$, without transitions in and out of a particular status (be it employment, unemployment or out of the labour market) in the interval (t; $t-1$ ) can be observed. This, clearly, represents a major concern in our analysis, given the interval considered across two subsequent periods is relatively long, i.e. one year. This limitation is likely to underestimate the degree of labour market turnover, especially for those individuals who often make transitions in and out of the labour market (e.g., part-time workers). A feasible alternative would be that of drawing on matched records across different LFS waves using national LFS data. However, the results might be anyway imprecise owing to the merging procedure and possible attrition and nonresponse issues, or errors in the classification of the labour market statuses across countries. For a discussion see Boeri and Flinn (1999).
} 
The anonymous nature of the LFS data does not allow tracking individuals over time. This breaks down any form of serial correlation between classification errors in our sample. In other words, reporting errors at a given survey date are independent of errors in previous LFS waves. Furthermore, we rule out the possibility that non-responses are captured as spurious changes in status, by necessarily excluding the number of individuals for which labour market classifications are not reported for the survey year and, retrospectively, for the year before. Finally, by construction of transition probabilities (i.e. the labour market status in the initial and the final period is the subjective assessment of the respondent's current and past working situation, reported at the time of the survey), any subjective bias between the "official" labour market status (i.e. as defined by the ILO) and its "reported" counterpart naturally simplifies out under the, likely, assumption that each individual's subjective bias is constant over time.

From the LFS, we construct raw probabilities of moving or remaining in any labour market status, together with an index of mobility (Shorrocks, 1987). Particularly, we consider nine possible transition probabilities across the statuses of employment, unemployment and out of the labour market (inactivity). The (ex post) probability of remaining in any particular labour market status is defined on the basis of the number of individuals being in that particular status $i$ in both year $\mathrm{t}$ and $\mathrm{t}-1$, as a percentage of individuals in the same status $i$ in year t-1. Conversely, the probability of moving from one labour market status to another is defined as the ratio of the probability of remaining in any labour market status $i$, as defined previously, over the probability of an individual in status $k$ in period (t-1) turning to status $i$ in period t.

For each country $(j)$ the probability of moving across $n$ labour market statuses between year $\mathrm{t}-1$ and year $\mathrm{t}$ is thus a $\left(\begin{array}{lll}n & x & n\end{array}\right)$ matrix $\left(P_{i, k}{ }^{j t}\right)$ in which each individual element $p_{i, k}^{j t}=\operatorname{Pr}\left\{S_{t}=i / S_{t-1}=k\right\}$ records the transition probability, with $i, k=$ employment $(e)$, unemployment $(u)$, out of the labour market or inactivity (na).

The measure of mobility used is the Shorrocks' (1987) mobility index, defined as: 
$M^{j t}=\left[n-\operatorname{trace}\left(P_{i, k}^{j t}\right)\right] /(n-1)$

By definition, the mobility index is bounded between $[0,1]$, where, a value of zero implies no probability of leaving any labour market status, and a value of one implies full mobility.

At this stage, it should be noted that flows from and into the labour market are very different among them. In fact, people moving from inactivity to unemployment are different from people moving from inactivity to employment, as the former re-enter the labour market but do not find a job immediately. In this vein, distinguishing between flows into and out of inactivity can be retained in the probability of successfully re-entering the labour market (Marston, 1976; Theeuwes et al., 1990). The latter is defined as:

$S L^{j t}=p_{\text {nan, },}^{j t} /\left(p_{\text {nan, }, e}^{j t}+p_{\text {nan }, u}^{j t}\right)$,

which is the percentage of people successfully entering the labour market $\left(p_{\text {nan,e }}\right)$ as a percentage of the number of people entering the labour market as a whole. Analogously, people leaving unemployment to get back into employment are different from those who, once separated from their job, stop searching for a new one (i.e. they move from unemployment into inactivity). Thus, unsuccessful labour market outcomes are computed as:

$F L^{j t}=p_{u, \text { nan }}^{j t} /\left(p_{u, \text { nan }}^{j t}+p_{u, e}^{j t}\right)$,

which is the percentage of people withdrawing from the labour market, as a percentage of people generally leaving unemployment (moving either back into employment or inactivity). It should be noted, however, that unsuccessful labour market outcomes may not represent labour market withdrawals per sé, as flows into inactivity also capture shifts into retirement or education. For this reason, when computing (un)successful labour market outcomes we control for 
the statuses of retirement and education. A discussion is warranted in the next section.

\section{$2.2 \quad$ Results}

Table 2 provides a snapshot of average transition probabilities, over time and across countries, between different labour market statuses during the period 1998-2008 for the euro area, CEE EU countries, Denmark and Sweden. The table shows that the average probability of being employed in year t-1 and year t, i.e. the probability of remaining employed for two consecutive periods, is $94 \%$ on average in the CEE EU countries and around $93 \%$ in Sweden and the euro area. The same probability is below 90\% in Denmark. The probability of remaining unemployed is around $60 \%$ in the euro area and CEE EU countries and about $40 \%$ in Denmark and Sweden. The probability of remaining inactive is between $85-90 \%$ in the euro area and the CEE EU countries but below $80 \%$ in Denmark and Sweden. Clearly, the probability of moving from employment to inactivity or the probability of moving from unemployment to inactivity is strongly associated with retirement flows and/or flows into the status of education. Controlling for education and retirement flows - setting up a 5dimensional transition matrix including the statuses of $e=$ employment, $u=$ unemployment, nan=inactivity (this time, excluding education and retirement), plus $i e=$ education and $r e=$ retirement - shows that the likelihood of remaining inactive (excluding retirement and education) for two consecutive periods falls to about $74 \%$ in Sweden. The same probability is about $77 \%$ in CEE EU countries and in Denmark and $84 \%$ in the euro area. ${ }^{8}$

\section{[Table 2 approximately here]}

\footnotetext{
${ }^{8}$ Those results are available upon request from the authors. An analysis of shifts into retirement or education is not provided here. For a discussion on retirement decisions see, inter alia, Aranki and Macchiarelli (2013).
} 
From Table 2, in the euro area and CEE EU countries the probability of moving from unemployment to employment is just below $30 \%$, compared with over $40 \%$ in Denmark and Sweden. In the CEE EU countries and the euro area this is much lower than the probability of remaining in unemployment. In Denmark and Sweden, however, an unemployed person has the same probability of finding a job as remaining unemployed.

Comparisons of labour transition probabilities over time shows that in the CEE EU countries the number of people remaining in unemployment has increased over the last decade, whereas it decreased in Sweden, the euro area, and, to a lesser extent, Denmark (Figure 1). ${ }^{9}$ For the euro area, of those individuals unemployed in period $\mathrm{t}-1$, the percentage remaining unemployed in period $\mathrm{t}$ decreased from $62 \%$ to $57 \%$. For Denmark this number decreased from $42 \%$ to $39 \%$ and for Sweden from $48 \%$ to $38 \%$. For CEE EU countries the same number increased instead from $57 \%$ to $61 \%$, possibly as the result of economic growth after 1998 not being very employment intensive, as evidenced by the number of people remaining in employment during the period 1998-2003, compared to the period 2004-2008. ${ }^{10}$

\section{[Figure 1 approximately here]}

By contrast, the probability of remaining inactive fell over time in the CEE EU countries, while it remained broadly stable in Sweden and the euro area, and increased somewhat in Denmark. Finally, the probability of remaining in employment increased strongly in the CEE countries as well as - but to a smaller degree - in Denmark and the euro area. In Sweden, the number of people remaining in employment decreased over the last decade.

Turning to transitions between different labour market statuses, the probability of moving from unemployment to employment is found to be very high in Denmark and Sweden, compared to the euro area and CEE EU countries, in

\footnotetext{
9 The probability of remaining in unemployment has increased in Czech Republic, Hungary, Poland, Romania and Slovakia over the last decade, but has fallen in the Baltic countries (Estonia, Latvia and Lithuania). In Latvia and Lithuania the fall in the probability of remaining in unemployment was accompanied by a higher probability of transiting from unemployment to inactivity over time, while for Estonia this probability remained roughly similar across time.

10 Changes in the institutional arrangements and labour market composition (also in the light of labour market migration to Western Europe stemming from the EU accession in 2004) have contributed to this trend.
} 
line, in the former case, with relatively fast hiring and firing dynamics compared to other continental EU labour markets. In addition, unemploymentto-employment flows have increased by about 7 percentage points over the last decade in both Denmark and Sweden (see Figure 1), while it remained constant in the CEE EU countries and slightly declined in the euro area. ${ }^{11}$ Flows in the opposite direction (i.e. unemployment to employment) have decreased overall in CEE countries, but also in Denmark, and, to a lesser extent, in Sweden and in the euro area.

The figures also shows that changes from unemployment to inactivity have overall fallen in the CEE EU countries, Denmark and Sweden where they strongly increased in the euro area. ${ }^{12}$ As for the euro area, a change in definition for France also explains such high rates of transition out of the labour market. ${ }^{13}$ The figure also suggests that transitions from inactivity into employment have decreased by about 2-3 percentage points in the CEE EU countries and Sweden, while they have decreased by less than 1 p.p. in Denmark and the euro area.

Looking at the percentage of people entering succesfully the labour market (succesful labour market entries, $S L$ ), we find that this percentage has increased in CEE EU countries (from $59 \%$ to $60 \%$ ), Denmark (from $60 \%$ to $67 \%$ ), and Sweden (from $71 \%$ to $76 \%$ ), while it has decreased in the euro area (from $64 \%$ to $58 \%$ ) over the period 1998-2008, controlling for education and retirement flows (i.e. in fact, the notation $p_{\text {nan,. }}{ }^{j t}$ in (2) refers to the number of people moving from inactivity (excluding retirement and education) into another state, and analogously for the formula in (3); see Table 3). Alternatively, the percentage of unsuccesful labour market outcomes $(U L)$ has decreased in CEE EU countries (from $33 \%$ to $31 \%$ ), Denmark (from $21 \%$ to $15 \%$ ) and Sweden (from $21 \%$ to $15 \%$ ). UL have increased only in the euro area (from $14 \%$ to

\footnotetext{
11 Country-specific results point to the fact that flows from employment to unemployment or inactivity do not vary much across countries, whereas movements from unemployment to employment or inactivity as well as transitions from inactivity to employment show more pronounced cross- country variation.

${ }^{12}$ A change in definition for France explains the high rates of transition into inactivity for the euro area aggregates. These results do not change when controlling for education and retirement transitions.

${ }^{13}$ Results for the euro area must be taken cautionsly, as the effect of this recodification can not be exactly quantified. As reported by the French National Institute of Statistics (INSEE) such an adjustment was adopted to make the unemployment definition conformable to the ILO criteria after 2003.For further details please see http://www.insee.fr/fr/methodes/sources/pdf/estimations_chomageBIT_enquete_emploi.pdf
} 
$26 \%$ ), net of transitions out of the labor market driven by education and retirement decisions. ${ }^{14}$

\section{[Table 3 approximately here]}

Turning to changes in labour market inflows and outflows by worker group (Figure 2), the reduction in people leaving the labour market in the CEE EU countries over the last decade was mainly driven by females, the highly educated and the 55 to 64 age group. At the same time, these countries experienced on average a reduction in people leaving inactivity and going back to the labour market, mainly driven by people between the ages of 15 and 24, males and low educated people. In Sweden the fall in the unemployment to inactivity and, viceversa inactivity to employment flows, is mostly driven by people between the ages of 15 and 24. In Denmark the mobility of highly educated people and the 25-29 age group support increasing participation rates, given that flows out of the labour market decreased and flows back into the labour market increased over the same period. For the euro area, excluding France, the number of people transitioning from unemployment to inactivity has overall decreased (in 2004-2008 against the period 1998-2003) on average, mainly triggered by females and highly educated workers. ${ }^{15}$ The probability of moving from inactivity to employment in the euro area decreased as well, driven by males and medium educated people, while it did not change much, or even increased (when including France), for female workers and people between the ages of $25-29$.

[Figure 2 approximately here]

\subsubsection{Labour mobility}

\footnotetext{
${ }^{14}$ Possibly, also in the light of the aforementioned change in definition for unemployment in France.

${ }^{15}$ From Figure 2, the results of labour market outflows increasing in the euro area are shown to be mainly driven by France, where the aforementioned change in the definition for unemployment is likely to over-estimate labour market quits. As reported by the French National Institute of Statistics (INSEE) such an adjustment was adopted to make the unemployment definition conformable to the ILO criteria after 2003.For further details please see http://www.insee.fr/fr/methodes/sources/pdf/estimations_chomageBIT_enquete_emploi.pdf
} 
Decomposing the results by worker group shows that the chance of unemployed youths finding a job is in all countries much higher than for older groups. Analogously, unemployment scarring (or the probability to remain in unemployment) is found to increase with age and is highest for individuals with lower educational attainment (Table 4).

\section{[Table 4 approximately here]}

Table 5 also provides a summary measure (the Shorrocks' index explained earlier) of labour market mobility. ${ }^{16}$ Importantly, the index summarizes the extent of the transitions between different economic activity statuses (employment, unemployment and inactivity).

\section{[Table 5 approximately here]}

The mobility index reflects an increase in labour market churning over time in Denmark, the euro area and, in particular, Sweden. On the contrary, the Shorrocks summary index for the periods 1998-2004 and 2004-2008 reveals a decrease in labour market mobility over time in the CEE EU countries. Following the changes in the labour market structure for some CEE EU, a high mobility during the period 1998- 2003 suggest higher returns to job changes and a less stringent labour market segmentation in the allocation of job offers after the reforms, as reported e.g., in Boeri and Flinn (1997). Conversely, the observed decline of mobility after 2004 - to values "converging" to what observed for the euro area - suggests a stabilization of labour markets in the region, but also a less efficient matching of individuals with jobs, as evidenced by the increase in the probability to remain in unemployment. ${ }^{17}$ In the euro area, Sweden, and, to lesser extent, Denmark, mobility increased over the whole

\footnotetext{
${ }^{16}$ As summarized before, the Shorrocks' index is a proxy index for mobility. For example, with respect to the results in Tables 2 and 3, the decrease in state persistence over time (i.e. the reduction of the elements on the main diagonal from 1998-2003 to 2004-2008) implies an increase in the mobility index across the two sub-periods.

${ }_{17}$ Particularly, the fall in mobility in the CEE EU countries from 2004 should be read in light of the political demand for social security after the transition period (early 90s). At that time several program of unemployment benefits, social security, income support and severance pay were put in place, with the (often mistaken) aim to enhance flexibility of workers and reduce long-term unemployment. Such active labour market spending seemed not to have crucially enhanced stagnation on unemployment pools before 2004 but, on the contrary, they seemed to create inefficiencies by means of displacement effects in the second period (2004-2008).
} 
period 1998-2008, essentially as the result of a fall in the probability of remaining in unemployment.

The mobility index also confirms that, in the euro area, mobility is particularly high for people between the ages of 25 and 29 and highly educated people, and has overall increased over time. Also, in the euro area mobility has generally increased for females, explaining the existence of no significant differences in the mobility index by gender (male vs. females) on a full period average. In the euro area, women and young people exhibit higher mobility over time through a decreasing probability to remain in both unemployment and inactivity. Analogously, highly educated workers are more mobile through a decreased probability to remain in unemployment over time.

From Table 5, in Denmark and Sweden people between the ages of 16-24 are the most mobile on average and their mobility has increased over time. Such behaviour is always driven by a lower probability of remaining in employment, unemployment and inactivity compared to the euro area aggregates (see Table 4). This pattern, which is also found for Finland - among other euro area countries, confirms a feature common to Nordic EU countries. In Sweden and Demark, highly educated individuals display both a higher probability of remaining in employment and a lower probability of remaining in unemployment and inactivity over time, while female workers display a lower probability of remaining in both employment and unemployment over time (Table 4).

In CEE EU countries mobility is higher for females, highly educated people and workers between the ages of 25 and 29, though this pattern has overall decreased over time. In these countries, the higher mobility of women is driven by a lower probability over time of remaining in employment and unemployment. Highly educated individuals in the CEE EU countries are more mobile through a lower probability over time of remaining in inactivity and employment.

\subsubsection{Pooling the results}


As well as over time, it is interesting to consider how labour market mobility and transitions varied across EU countries and workers groups. While some empirical patterns are observed in all countries (e.g. the probability of remaining unemployed is several times higher than the probability of an employed individual turning unemployed), cross-country differences in the degree of mobility among different labour market statuses do exist. Particularly, by pooling results, we find that the probability of remaining in employment and, to a lesser extent, inactivity over two periods ( $t-1$ and t) is very similar across countries (Figure 3). The results also emphasises the very small variation across countries in the low probability of moving from employment into either unemployment or inactivity. Significant differences across countries are found in the probability of remaining unemployed over two consecutive periods, and in the transitions out of unemployment. Looking at cross-country differences, the probability of remaining unemployed is on average over $70 \%$ in, Belgium, Greece and Slovenia, or slightly below in Italy, Bulgaria, Latvia and Slovakia. This probability is almost twice that of the probability in Denmark, Sweden, Spain, the Netherlands and Cyprus and more than two-thirds that of the probability in France, Austria, Portugal, Estonia and Romania. This probability is around $60 \%$ in Finland, Czech Republic, Lithuania, Hungary and Poland and about only $24 \%$ in Luxembourg.

\section{[Figure 3 approximately here]}

Furthermore, while the probability of remaining in unemployment has increased over time in Italy, Portugal, Cyprus, Czech Republic, Hungary, Poland, Romania and Slovakia, it has fallen in Belgium, Greece, France, Austria, Slovenia, the Baltic countries (Estonia, Latvia and Lithuania), Denmark and Sweden (Table 6).

[Table 6 approximately here] 
Further, on the basis of the Shorrocks' mobility index, labour markets in some countries are characterised by more mobility than others (see Table 7). As expected, labour markets in Denmark and Sweden are more mobile on average, together with that of Spain, the Netherlands, France and Luxemburg. This is evidenced by a higher Shorrocks' mobility index, which is twice as high in these countries relative to Bulgaria, the Slovak Republic, Poland, Latvia, Hungary, Italy, Belgium, Greece and Slovenia. A group of countries reporting intermediate mobility is represented instead by the Czech Republic, Estonia, Lithuania, Romania, Austria, Finland, Cyprus and Portugal. Table 7 also shows that on average highly educated individuals and people between the ages of 25-29 are the most mobile across labour market statuses. Moreover, while for Denmark, Sweden and the euro area mobility of all worker groups has increased over the last decade (particularly for females) there is no clear pattern for the disaggregated CEE EU countries. The highest mobility groups overall are the 16 to 24 age group in Denmark and Sweden, the 25 to 29 year olds in Romania, people with high educational attainment in the Slovak Republic, the 25 to 29 age group in Spain and the 16-24 age group in Finland (Table 7).

\section{[Table 7 approximately here]}

\section{WHAT'S BEHIND MOBILITY? A QUICK LOOK}

While the analysis carried out in earlier was aimed at providing a description of the degree of labour market turnover in the EU, in this section we complement this information by looking at macroeconomic trends in employment (both part-time and temporary), unemployment and the evolution of structure indicators (EPL, product market regulation, etc.). Our objective is to understand whether part of the observed changes in mobility can be broadly restraint to some "macro" explanatory factors.

Not surprisingly, the increase in mobility observed in some countries can be linked to the use of time-limited contracts and part-time work, and viceversa. Figure 4 (top and medium panels) shows that, broadly speaking, those 
countries where mobility increased over time are also those where the percentage of time limited contracts and part time work increased. However, the correspondence is not one-to-one. Further, Latvia represents a major exception, as the observed increase in mobility is not found to be associated with an increase in the share of temporary or part-time jobs.

\section{[Figure 4 approximately here]}

In addition, there is no clear correspondence between unemployment rate and mobility. In most countries increases in mobility are associated with a reduction of unemployment over time (Figure 4, bottom panel). Overall, however, in some countries mobility decreased and so too did unemployment rates (notably, Slovakia, Italy, Poland and the Czech Republic), suggesting that while a certain level of turnover is necessary for healthy labour markets (see also Boeri and Garibaldi, 2009), it may not be sufficient (also depending on the direction in which changes in labour market statuses are observed; see Section 2).

Focusing on structure indicators (Figure 5), changes in mobility over time seem to be negatively related with changes in the strictness of Employment Protection Legislation $(\mathrm{EPL}),{ }^{18}$ i.e. less regulation favours labour market turnovers and viceversa, especially in Sweden, Czech Republic and Poland. A similar pattern does not exist for Italy and Portugal, among the euro area countries, or Slovakia. Further, changes in the mobility index are, in most cases, correlated with changes in the expenditure on 'active' labour market policies, such as direct job creation, and, to a lesser extent, employment incentives. ${ }^{19}$ A reduction in direct job-creation expenditures is associated with decreasing mobility over time in Italy and Portugal - among the euro area countries - and Slovakia. On the contrary, in France and Sweden a reduction in direct-job creation expenditure is positively associated with increased mobility.

\footnotetext{
${ }^{18} \mathrm{EPL}$ is likely to proxy institutional factors such as the degree of unionization, minimum wage policies, etc.

${ }^{19}$ With employment incentives we mean benefits paid to beneficiaries with low earning from part-time or intermittent jobs. See OECD.stat database.
} 
The expenditure on out-of-work maintenance and support (including unemployment benefits, expenditure on early retirement, ${ }^{20}$ etc...) is found to be negatively related with mobility over time. This is particularly clear for countries such as Italy, Portugal and Sweden, where increases (decreases) in the expenditure on out-of-work benefits are coupled with lower (higher) mobility over time. Poland and Slovakia provide the opposite picture.

\section{[Figure 5 approximately here]}

Finally, a decrease in product market regulation is related with increased mobility over time in almost all countries - with the exceptions of Italy and Portugal - among euro area countries - and mainly Poland, Czech Republic and Slovakia - among the CEE EU countries. ${ }^{21}$

\section{CONCLUDING REMARKS}

This paper presented information on labour market mobility in $23 \mathrm{EU}$ countries for the period 1998 to 2008 using Eurostat Labour Force Survey (LFS) data. The analysis presented evidence by country and worker group.

Transitions from unemployment and inactivity back into employment are found to be less frequent in the CEE EU and the euro area than in Denmark and Sweden. Moreover, in the euro area, Sweden, and, to a lesser extent, Denmark, the number of people remaining in unemployment decreased over the period 1998-2008 whereas this number increased in the average CEE EU countries. At the same time, however, successful labour market entries (from outside the labour market) increased in CEE EU countries, Denmark and Sweden.

Summary mobility measures for the periods 1998 - 2004 and $2004-2008$ show a decrease in labour market mobility over time in the CEE EU countries and an increase in Denmark, Sweden and the euro area. This decline of labour market

\footnotetext{
20 This type of expenditure refers to a scheme which allows (older) workers - already on unemployment benefits - to move to a similar benefit scheme where the work availability requirement is no longer necessary.

21 For the former, the patters is, however, in line with the idea that a higher regulation is expected to reduce employment by slowing down the pace at which displaced workers find new jobs (see also Burgess et al., 2000), resulting into a lower level of labour turnover.
} 
mobility in the CEE countries, while reflecting a stabilization of labour markets, may stem from a less efficient matching of individuals with jobs than in other countries, as evidenced by an increase in the probability to remain in unemployment. In contrast, in the euro area, Sweden, and to a lesser extent, Denmark, mobility increased over this period, essentially as the result of a fall in the probability of remaining in unemployment. All in all, the highest degree of labour market mobility among the countries covered in this paper is consistently observed in Spain, Luxemburg, the Netherlands, Denmark and Sweden, with these results mainly reflecting higher mobility of people below the age of 29 , highly educated and female workers. We also find that mobility of all worker groups has generally increased over time in the euro area, Denmark and Sweden.

Looking at some explanatory factors, the results suggest that countries who experienced an increase in mobility are also those which increased their percentage of time limited (e.g., temporary) contracts and part time work, and viceversa. However, looking at unemployment rates and some structure indicators the results provide a mixed picture, suggesting that the sense of mobility strongly varies across countries. ${ }^{22}$

\section{REFERENCES}

[1] Aranki T., Macchiarelli C. (2013), Employment duration and shifts into retirement in the EU, Working Paper Series 1517, European Central Bank.

[2] Boeri T., Flinn c.J. (1997), "Return sto Mobility in the Transition to a Market Economy", Manuscript.

[3] Boeri T., Garibaldi P. (2009), "Beyond Eurosclerosis", Economic Policy, pp. 409-461.

[4] Burgess S. et al. (2000), "Employment and Output Adjustment in the OECD: A Disaggregate Analysis of the Role of Job Security Provisions," Economica, London School of Economics and Political Science, vol. 67(267), pages 419-35.

\footnotetext{
22 As discussed in Section 2, also depending on the direction in which transitions across labour market statuses are observed - be it from unemployment to employment, from unemployment to inactivity and so on. The effectiveness of labour market measures and their interactions are likely to affect the degree of labour market turnover as well.
} 
[5] Caliendo M., Uhlendorff A., (2008), "Self-Employment Dynamics, State Dependence and Cross-Mobility Patterns", IZA Working Paper, no. 3900.

[6] Elsby M. et al.(2008), "Unemployment Dynamics in the Oecd", NBER Working Paper Series, no. 14617.

[7] Epstein N., Macchiarelli C. (2010), Estimating Poland's Potential Output: A Production Function Approach, IMF Working Paper WP/10/15

[8] European Commission, (2010), "Labour market and wage development in 2009", Economic and Financial Affairs.

[9] Fujita S., Ramey G., (2006), "The Cyclicality of Job Loss and Hiring", Federal Reserva Bank of Philadelphia Working Paper, no. 06-17.

[10] Fujita S., Ramey G., (2009), "The Cyclicality of Separation and Job Finding Rates", International Economic Review, no. 50, vol. 2(05), pp. 415430.

[11] Macchiarelli C. (2013a), GDP-Inflation cyclical similarities in the CEE countries and the euro area, Working Paper Series 1552, European Central Bank.

[12] Macchiarelli C. (2013b), Similar GDP-inflation cycles. An application to CEE countries and the euro area, Research in International Business and Finance, 27(1), 124-144.

[13] Marston, S.T. (1976) Employment instability and high unemployment rates. Brookings Papers on Economic Activity 169-203.

[14] Theeuwes J. et al. (1990), "Transition intensities in the Dutch labour market 1980-85", Applied Economics, vol. 22.

[15] Shimer R., (2005), "Reassessing the Ins and Outs of Unemployment", NBER Working Paper, no. 13421.

[16] Petrangolo B., Pissarides C., (2008), "The Ins and Outs of European Unemployment", IZA Working Paper, no. 3315. 
Table 1: Unemployment and employment rates in the EU (1998-2008)

\begin{tabular}{|c|c|c|c|c|}
\hline $\begin{array}{l}\text { EU } \\
\text { (changing } \\
\text { composition) }\end{array}$ & $\begin{array}{c}\text { Unemployment rate } \\
(\%)\end{array}$ & $\begin{array}{l}\text { Long-term } \\
\text { unemployment } \\
\text { (12 months or } \\
>\text { ) } \\
\text { as a } \% \text { of the } \\
\text { total } \\
\text { unemployment }\end{array}$ & $\begin{array}{c}\text { Employment } \\
\text { rate } \\
(\%) \\
\end{array}$ & $\begin{array}{c}\text { Average } \\
\text { unemployment } \\
\text { duration in } \\
\text { months }\end{array}$ \\
\hline 1998 & 10.3 & 48.0 & 61.2 & 18.3 \\
\hline 1999 & 9.5 & 46.1 & 62.2 & 17.7 \\
\hline 2000 & 8.5 & 45.4 & 63.2 & 17.4 \\
\hline 2001 & 7.4 & 44.0 & 63.9 & 16.0 \\
\hline 2002 & 7.7 & 40.1 & 64.2 & 15.6 \\
\hline 2003 & 8.1 & 41.3 & 64.4 & 16.1 \\
\hline 2004 & 8.3 & 41.0 & 64.6 & 15.7 \\
\hline 2005 & 9.1 & 45.5 & 64.0 & 15.7 \\
\hline 2006 & 8.3 & 45.3 & 64.8 & 15.7 \\
\hline 2007 & 7.2 & 42.7 & 65.4 & 14.8 \\
\hline 2008 & 7.1 & 37.0 & 65.9 & 12.4 \\
\hline \multicolumn{5}{|c|}{ EA (16 countries) } \\
\hline 1998 & .. & .. & .. & \\
\hline 1999 & .. & .. & .. & \\
\hline 2000 & 9.4 & 48.6 & 61.2 & \\
\hline 2001 & 8.3 & 47.3 & 62.0 & \\
\hline 2002 & 8.6 & 43.7 & 62.3 & \\
\hline 2003 & 9.0 & 45.0 & 62.6 & \\
\hline 2004 & 9.3 & 44.6 & 62.8 & \\
\hline 2005 & 9.1 & 45.3 & 63.7 & \\
\hline 2006 & 8.4 & 46.2 & 64.6 & \\
\hline 2007 & 7.6 & 44.3 & 65.6 & \\
\hline 2008 & 7.6 & 39.3 & 66.0 & \\
\hline
\end{tabular}

Sources: Eurostat and OECD statistics (last column). 
Table 2: Transition probabilities (full period, 1998 - 2008)

\begin{tabular}{|c|c|c|c|c|c|c|c|c|c|c|c|c|c|c|}
\hline & & \multicolumn{13}{|c|}{$\begin{array}{c}\text { Labour market status } \\
\text { year t }\end{array}$} \\
\hline \multirow{13}{*}{$\begin{array}{c}\text { Labour } \\
\text { market } \\
\text { status }\end{array}$} & & \multicolumn{4}{|c|}{ CEE EU } & \multicolumn{3}{|c|}{ Denmark } & \multicolumn{3}{|c|}{ Sweden } & \multicolumn{3}{|c|}{ Euro area } \\
\hline & & $1998-2008$ & $\mathrm{E}$ & $\mathrm{U}$ & NA & $\mathrm{E}$ & $\mathrm{U}$ & NA & $\mathrm{E}$ & $\mathrm{U}$ & NA & $\mathrm{E}$ & $\mathrm{U}$ & NA \\
\hline & & $\overline{\mathrm{E}}$ & 94.051 & 3.125 & 3.420 & 89.427 & 2.434 & 8.337 & 93.273 & 2.269 & 4.624 & 93.860 & 3.111 & 3.177 \\
\hline & & $\mathrm{U}$ & 28.514 & 60.799 & 14.697 & 42.044 & 40.266 & 19.122 & 42.940 & 42.042 & 19.478 & 29.937 & 61.667 & 11.721 \\
\hline & & $\mathrm{NA}$ & 7.323 & 3.880 & 86.052 & 15.908 & 3.883 & 80.462 & 17.734 & 6.141 & 76.695 & 6.854 & 3.593 & 89.911 \\
\hline & & 1998-2003 & $\mathrm{E}$ & $\mathrm{U}$ & NA & $\mathrm{E}$ & $\mathrm{U}$ & $\mathrm{NA}$ & $\mathrm{E}$ & $\mathrm{U}$ & $\mathrm{NA}$ & $\mathrm{E}$ & $\mathrm{U}$ & NA \\
\hline & 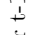 & $\overline{\mathrm{E}}$ & 92.462 & 4.406 & 4.299 & 88.829 & 2.803 & 8.396 & 94.026 & 2.325 & 3.849 & 93.728 & 3.153 & 3.083 \\
\hline & $\ddot{\tilde{\Xi}}$ & $\mathrm{U}$ & 28.431 & 57.021 & 16.023 & 37.333 & 42.165 & 22.100 & 36.301 & 48.783 & 19.738 & 30.694 & 62.104 & 7.773 \\
\hline & & NA & 8.959 & 4.996 & 87.560 & 16.065 & 4.417 & 79.660 & 19.578 & 5.401 & 76.600 & 7.441 & 3.478 & 89.916 \\
\hline & & $2004-2008$ & $\mathrm{E}$ & $\mathrm{U}$ & $\mathrm{NA}$ & $\mathrm{E}$ & $\mathrm{U}$ & NA & $\mathrm{E}$ & $\mathrm{U}$ & NA & $\mathrm{E}$ & $\mathrm{U}$ & NA \\
\hline & & $\overline{\mathrm{E}}$ & 94.360 & 2.702 & 2.902 & 89.580 & 2.227 & 8.321 & 92.949 & 2.244 & 4.878 & 93.933 & 2.885 & 3.208 \\
\hline & & $\mathrm{U}$ & 28.538 & 61.396 & 13.914 & 43.972 & 39.226 & 17.558 & 44.778 & 38.781 & 19.400 & 29.557 & 57.289 & 13.353 \\
\hline & & NA & 6.602 & 3.448 & 86.046 & 15.857 & 3.619 & 80.654 & 17.063 & 6.323 & 76.731 & 6.792 & 3.670 & 89.554 \\
\hline
\end{tabular}

Note: $\mathrm{E}=$ employed; $\mathrm{U}=$ unemployed; $\mathrm{NA}=$ inactive so that $\mathrm{EE}=$ remains in employment between one year and the next; $\mathrm{UU}=$ remains in unemployment, NANA = remains in inactivity. For CEE EU and euro area countries observations are weighted according to the labour force share (15-64) in each country over the aggregate. Elements showing a probability of remaining in the same labour market state (employment, unemployment and inactivity) are in bold.

Sources: LFS microdata, authors' computations.

Table 3: Successful and unsuccessful labour market outcomes

\begin{tabular}{|c|c|c|c|c|}
\hline & CEE EU & nmark & Sweden & Euro area \\
\hline & \multicolumn{4}{|c|}{ Successful labour market outcome } \\
\hline $1998-2003$ & 59.432 & 60.021 & 71.017 & 64.083 \\
\hline \multirow[t]{2}{*}{ 2004-08 } & 60.378 & 66.767 & 76.091 & 57.745 \\
\hline & \multicolumn{4}{|c|}{ Unsuccessful labour market outcome } \\
\hline 1998 & 33.466 & 20.444 & 20.907 & 14.433 \\
\hline 2004-08 & 31.275 & 14.471 & 15.517 & 26.167 \\
\hline
\end{tabular}

Note: Results are based on a 5-dimensional transition probability matrix where statuses are defined as $\mathrm{E}=$ employed; $\mathrm{U}=$ unemployed; $\mathrm{NAN}=$ inactive (excluding education and retirement); $\mathrm{RE}=\mathrm{in}$ retirement; $\mathrm{IE}=\mathrm{in}$ education. Compared to the results where a 3-dimensional transition matrix is used (with $\mathrm{E}=$ employed; $\mathrm{U}=$ unemployed; $\mathrm{NA}=$ inactive), the results here holds in the light of $\mathrm{NA}=\mathrm{NAN}+\mathrm{IE}+\mathrm{RE}$. In other words, in computing successful and unsuccessful labour market outcomes we control for education and retirement flows when defining the status of inactivity. Following Theeuwes et al. (1990) a successful labour market entry is computed as the percentage of people successfully entering the labour market $\left(p_{\text {nan }, e}\right)$ as a percentage of the total number of people entering the labour market, i.e. $S L^{j t}=p_{\text {nan }, e}{ }^{j t} /\left(p_{\text {nan }, e}^{j t}+p_{\text {nan }, u}^{j t}\right)$.

Analogously, an unsuccessful labour market outcome is the percentage of people withdrawing from the labour market (but not moving to either retirement or education), as a percentage of people leaving unemployment, i.e. $F L^{j t}=p_{u, \text { nan }}^{j t} /\left(p_{u, \text { nan }}^{j t}+p_{u, e}{ }^{j t}\right)$.

Sources: LFS microdata, authors' computations. 
Table 4: Transition probabilities by worker group

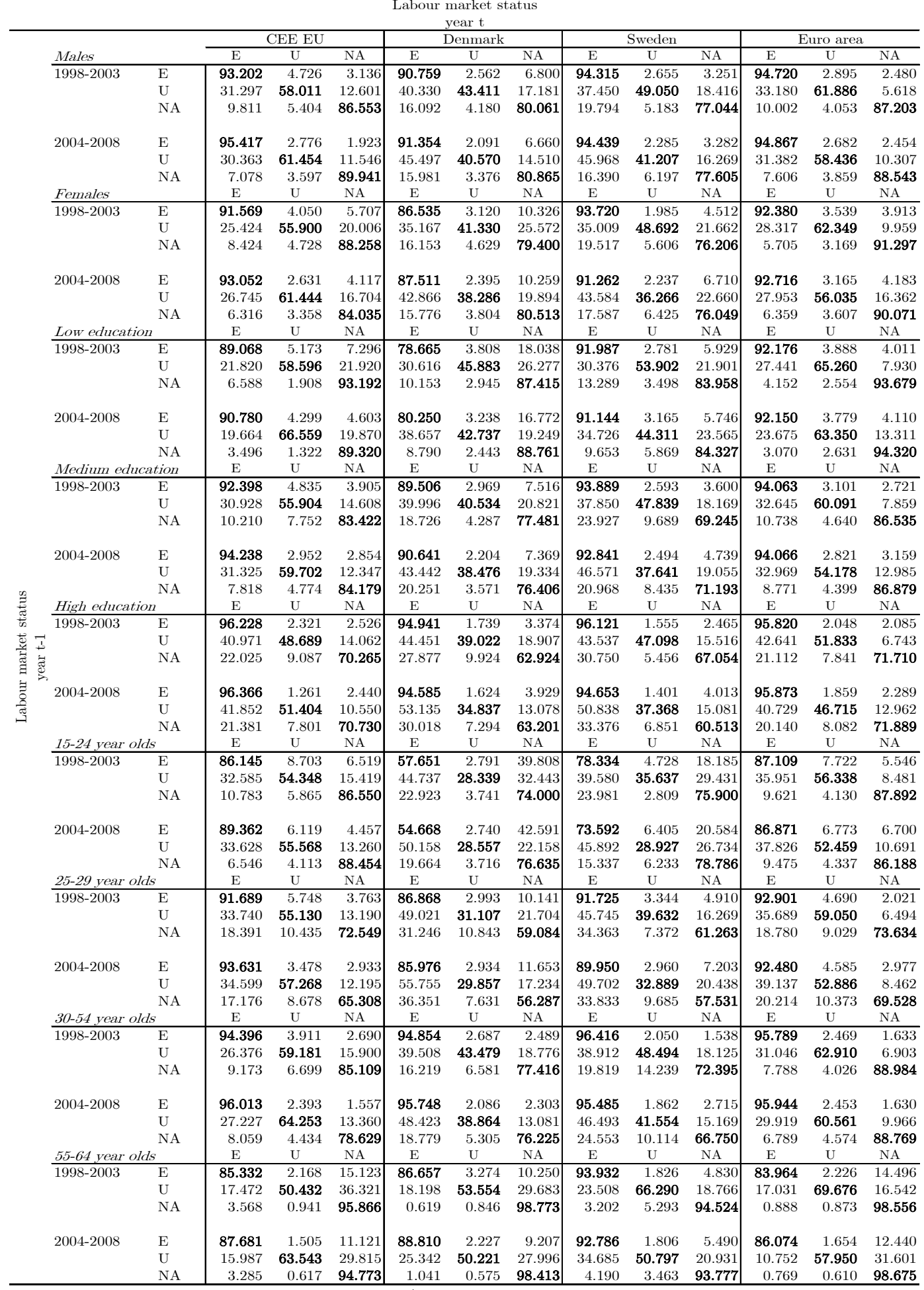

Note: $\mathrm{E}=$ employed; $\mathrm{U}=$ unemployed; $\mathrm{NA}=$ inactive so that $\mathrm{EE}=$ remains in employment between one year and the next; $\mathrm{UU}=$ remains in unemployment, NANA = remains in inactivity. For CEE EU and euro area countries observations are weighted according to the labour force share (15-64) in each country over the aggregate. Elements showing a probability of remaining in the same labour market state (employment, unemployment and inactivity) are in bold.

Sources: LFS microdata, authors' computations. 
Table 5: Mobility index

\begin{tabular}{|c|c|c|c|c|c|}
\hline & & CEE EU & Denmark & Sweden & Euro area \\
\hline \multirow[t]{3}{*}{ Total } & $1998-2003$ & 0.315 & 0.447 & 0.403 & 0.271 \\
\hline & $2004-2008$ & 0.291 & 0.453 & 0.458 & 0.296 \\
\hline & Total & 0.295 & 0.449 & 0.440 & 0.272 \\
\hline \multirow[t]{3}{*}{ Males } & 1998-2003 & 0.311 & 0.429 & 0.398 & 0.281 \\
\hline & $2004-2008$ & 0.266 & 0.436 & 0.434 & 0.291 \\
\hline & Total & 0.273 & 0.433 & 0.422 & 0.276 \\
\hline \multirow[t]{3}{*}{ Females } & $\begin{array}{l}1998-2003 \\
\end{array}$ & 0.321 & 0.464 & 0.407 & 0.270 \\
\hline & 2004-2008 & 0.307 & 0.468 & 0.482 & 0.306 \\
\hline & Total & 0.311 & 0.465 & 0.459 & 0.275 \\
\hline \multirow[t]{3}{*}{ Low-education } & $\begin{array}{l}1998-2003 \\
\end{array}$ & 0.296 & 0.440 & 0.351 & 0.244 \\
\hline & $2004-2008$ & 0.267 & 0.441 & 0.401 & 0.251 \\
\hline & Total & 0.264 & 0.438 & 0.382 & 0.234 \\
\hline \multirow[t]{3}{*}{ Medium-education } & $\begin{array}{l}1998-2003 \\
\end{array}$ & 0.341 & 0.462 & 0.445 & 0.297 \\
\hline & 2004-2008 & 0.309 & 0.472 & 0.492 & 0.324 \\
\hline & Total & 0.315 & 0.468 & 0.476 & 0.303 \\
\hline \multirow[t]{3}{*}{ High-education } & $\begin{array}{l}1998-2003 \\
\end{array}$ & 0.424 & 0.516 & 0.449 & 0.403 \\
\hline & 2004-2008 & 0.408 & 0.537 & 0.537 & 0.428 \\
\hline & Total & 0.408 & 0.531 & 0.514 & 0.408 \\
\hline \multirow[t]{3}{*}{ 16-24 years olds } & $\begin{array}{l}1998-2003 \\
\end{array}$ & 0.365 & 0.700 & 0.551 & 0.343 \\
\hline & $2004-2008$ & 0.333 & 0.701 & 0.593 & 0.372 \\
\hline & Total & 0.337 & 0.700 & 0.582 & 0.359 \\
\hline \multirow[t]{3}{*}{$25-29$ years olds } & $\begin{array}{l}1998-2003 \\
\end{array}$ & 0.403 & 0.615 & 0.537 & 0.372 \\
\hline & 2004-2008 & 0.419 & 0.639 & 0.598 & 0.426 \\
\hline & Total & 0.412 & 0.631 & 0.579 & 0.397 \\
\hline \multirow[t]{3}{*}{$30-54$ years olds } & $\begin{array}{l}1998-2003 \\
\end{array}$ & 0.307 & 0.421 & 0.413 & 0.261 \\
\hline & $2004-2008$ & 0.306 & 0.446 & 0.481 & 0.274 \\
\hline & Total & 0.305 & 0.437 & 0.460 & 0.258 \\
\hline \multirow[t]{3}{*}{$55-64$ years olds } & $\begin{array}{l}1998-2003 \\
\end{array}$ & 0.342 & 0.305 & 0.226 & 0.239 \\
\hline & 2004-2008 & 0.270 & 0.313 & 0.313 & 0.287 \\
\hline & Total & 0.279 & 0.309 & 0.281 & 0.224 \\
\hline
\end{tabular}

Notes: Measures are based on the Shorrocks' mobility index (mobility is higher the closer the index is to 1). For CEE EU and euro area countries observations are weighted according to the labour force share (15-64) in each country over the CEE EU and euro area aggregate, respectively.

Sub-groups are weighted instead according to the proportion in each country of each subcategory (males, females, low, medium, high education,..) over the CEE EU and euro area aggregate, respectively. Highest mobility indexes for each sub-category across the periods 1998-2003 and 2004-2008 are in bold.

Sources: LFS microdata, authors' computations. 
Table 6: Transition probabilities across country

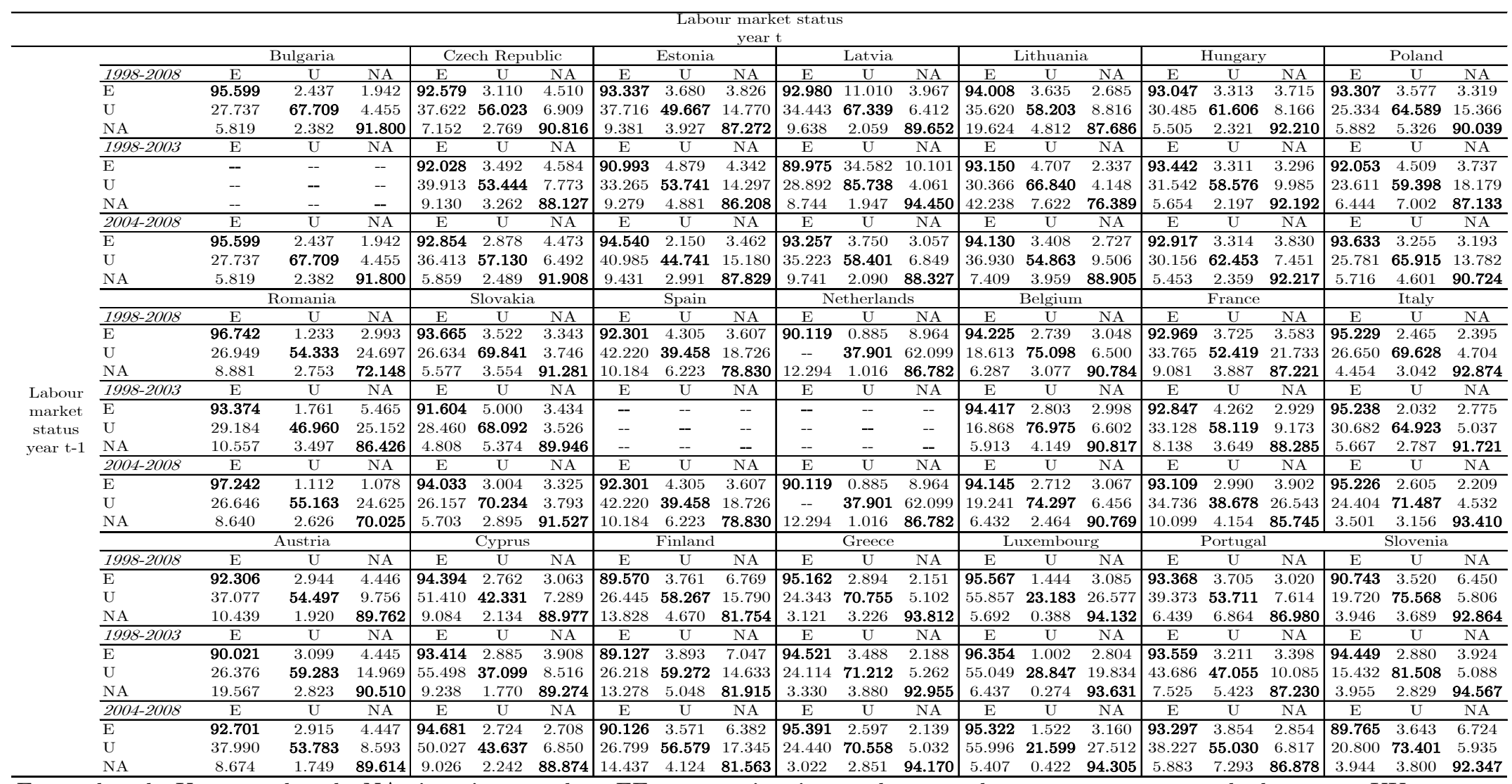

Note: $\mathrm{E}=$ employed; $\mathrm{U}=$ unemployed; $\mathrm{NA}=$ inactive so that $\mathrm{EE}=$ remains in employment between one year and the next; UU = remains in unemployment, NANA = remains in inactivity. For CEE EU and euro area countries observations are weighted according to the labour force share (15-64) in each country over the aggregate. Elements showing a probability of remaining in the same labour market state (employment, unemployment and inactivity) are in bold. The results exclude Denmark and Sweden (see Table 2).

Sources: LFS microdata, authors' computations. 
Table 7: Mobility index across country and worker group

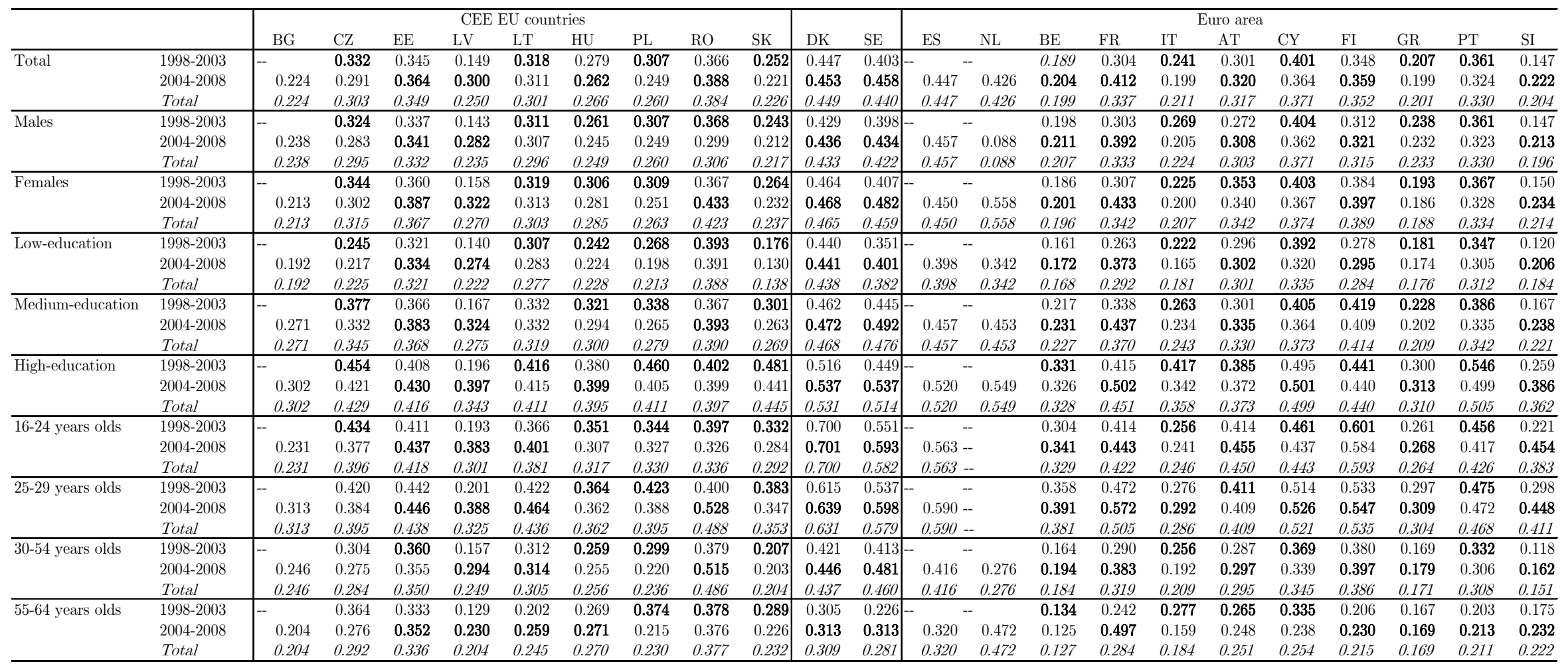

Notes: Measures are based on the Shorrocks' mobility index. Highest mobility indexes for each sub-category across the periods 1998-2003 and 2004-2008 are in bold. The table refers to 23 EU countries: Spain (ES), Italy (IT), France (FR), the Netherlands (NL), Belgium (BE), Austria (AT), Cyprus (CY), Finland (FI), Greece (GR), Luxemburg (LU), Portugal (PT), Slovenia (SI); Czech Republic (CZ), Estonia (EE), Latvia (LV), Lithuania (LT), Hungary (HU), Poland (PL), Romania (RO) and Slovakia (SK); Denmark (DK) and Sweden (SE).

Sources: LFS microdata, authors' computations. 
Figure 1: Changes in transition probabilities over time

(2004-2008 minus 1998-2003)
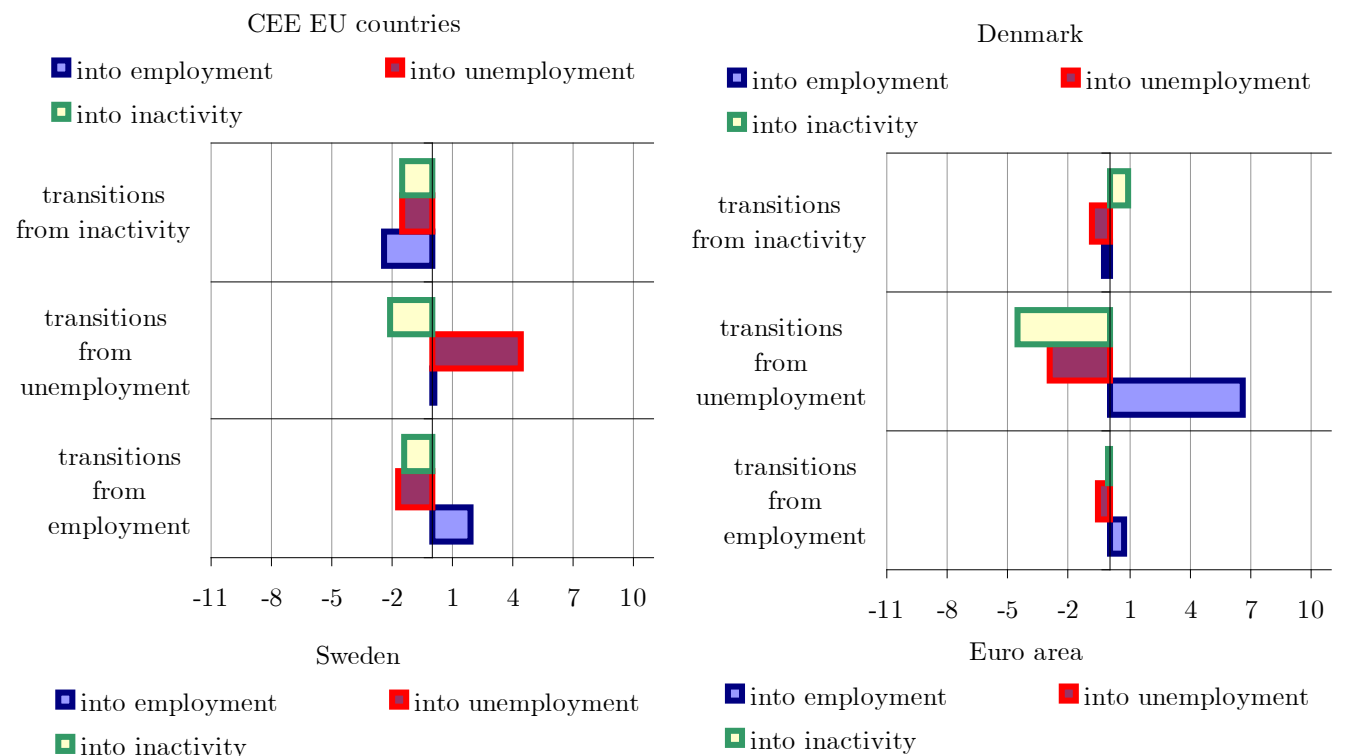

口into employment

口into unemployment

口into inactivity

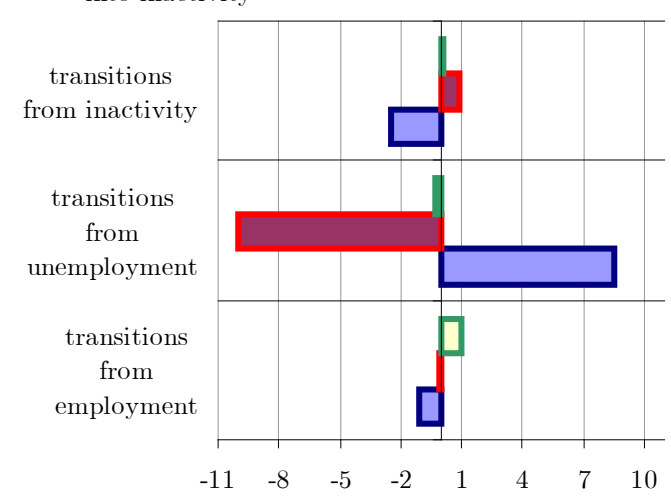

口into inactivity

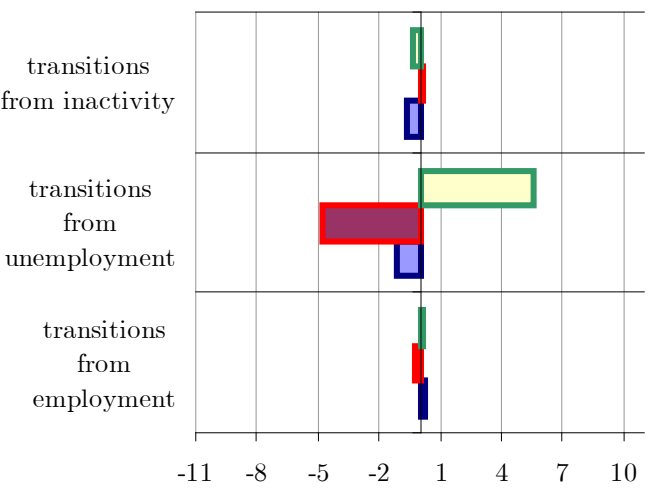

Sources: LFS microdata, authors' computations. 
Figure 2: Changes in the probability of moving from unemployment to inactivity (lhs) and in the probability of moving from inactivity to employment (rhs).

(2004-2008 minus 1998-2003).
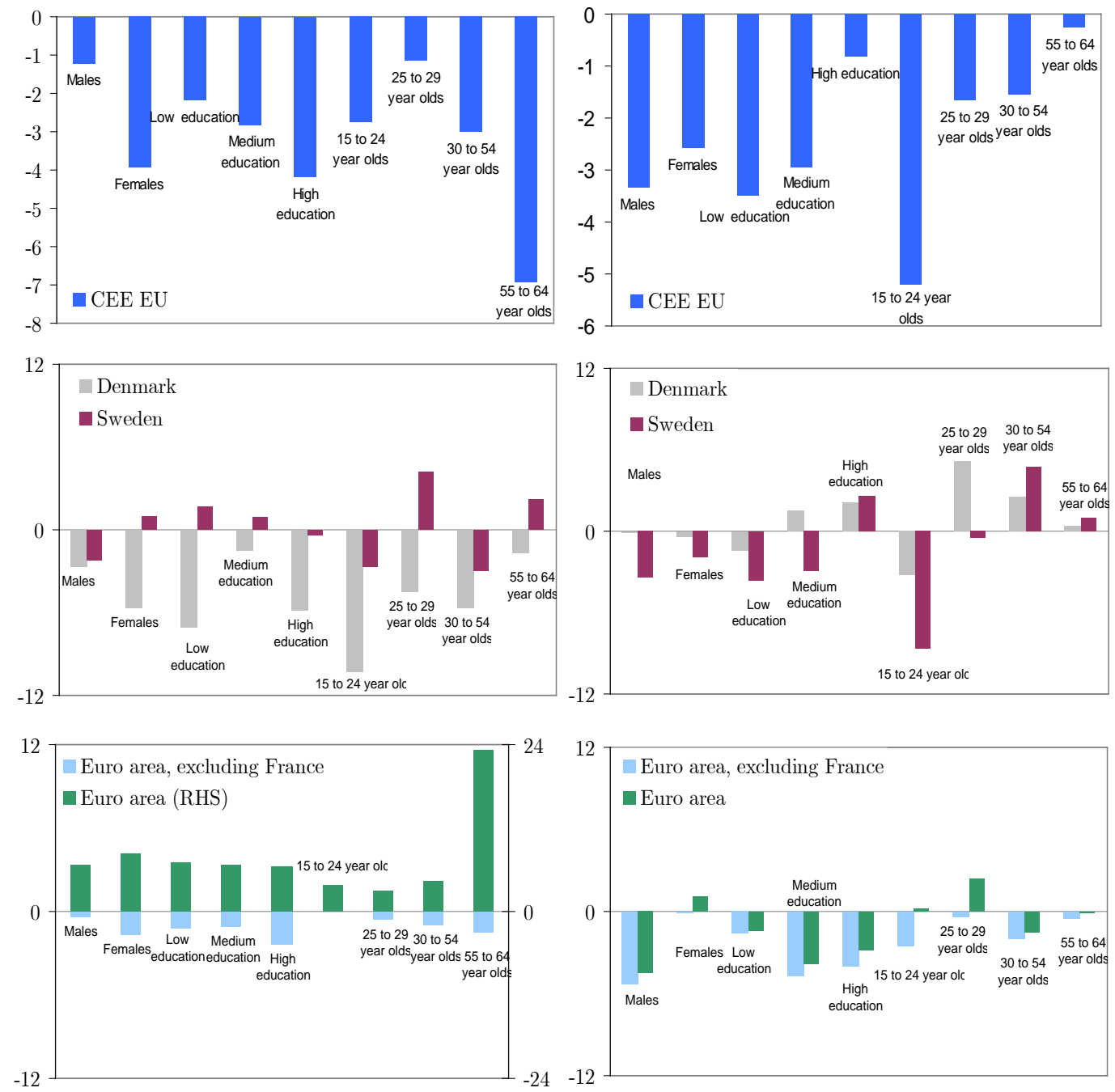

Note: The chart on the lhs presents the percentage change in unemployment to inactivity flows by different workers groups. For the CEE EU and the euro area bars refer to a weighted country average, where observations are weighted according to the proportion in each country of each sub-category (males, females, low, medium, high education,...) over the CEE EU and euro area aggregate, respectively. The chart on the rhs presents inactivity to employment reshuffles under the same reasoning.

Sources: LFS microdata, authors' computations. 
Figure 3: Transition probabilities across countries
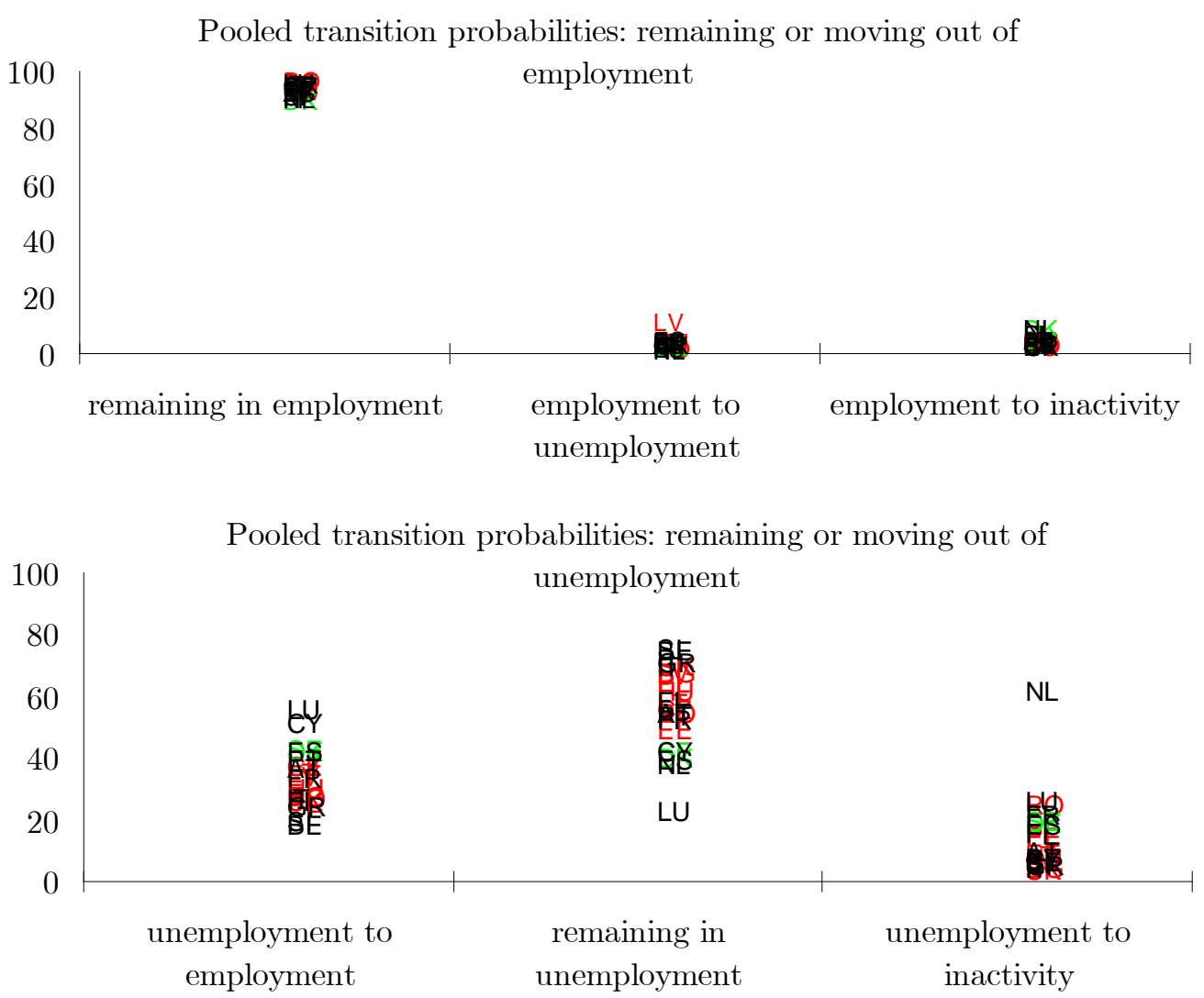

Pooled transition probabilities: remaining or moving out of inactivity

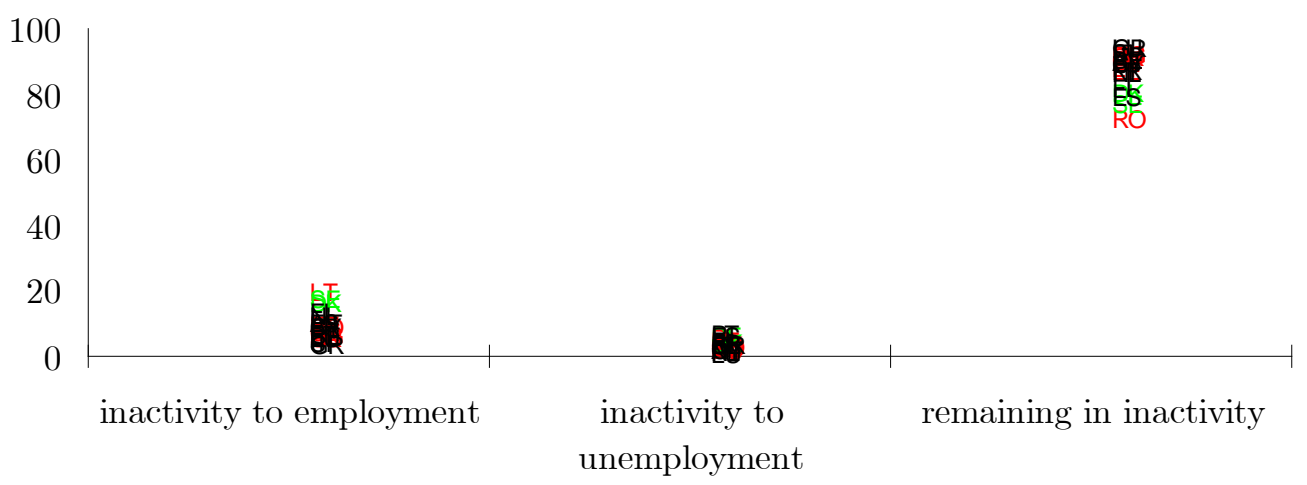

Notes: The chart refers to pooled transition probabilities results for $23 \mathrm{EU}$ countries. Euro area countries (black label): Spain (ES), Italy (IT), France (FR), the Netherlands (NL), Belgium (BE), Austria (AT), Cyprus (CY), Finland (FI), Greece (GR), Luxemburg (LU), Portugal (PT), Slovenia (SI); CEE EU countries (red label): Czech Republic (CZ), Estonia (EE), Latvia (LV), Lithuania (LT), Hungary (HU), Poland (PL), Romania (RO) and Slovakia (SK); Denmark (DK) and Sweden (SE) (green label).

Sources: LFS microdata, authors' computations. 
Figure 4: Mobility index vs. employment and unemployment
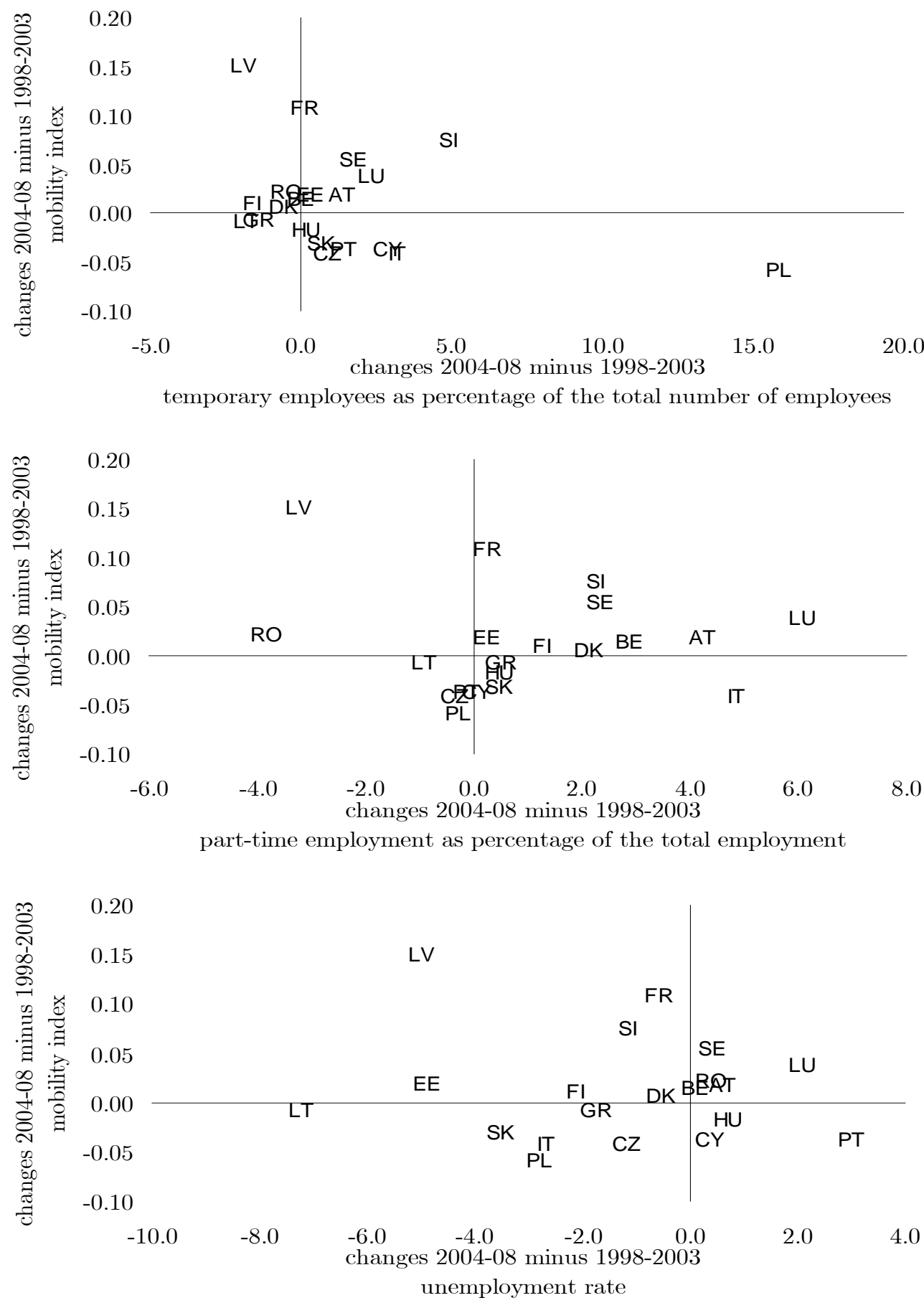

Notes: Where available, the chart refers to pooled transition probabilities results for 23 EU countries. Spain (ES), Italy (IT), France (FR), the Netherlands (NL), Belgium (BE), Austria (AT), Cyprus (CY), Finland (FI), Greece (GR), Luxemburg (LU), Portugal (PT), Slovenia (SI); Czech Republic (CZ), Estonia (EE), Latvia (LV), Lithuania (LT), Hungary (HU), Poland (PL), Romania (RO) and Slovakia (SK); Denmark (DK) and Sweden (SE). Changes for the variables on the x-axis are the difference between 2004-08 and 1998-2003 averages.

The results are not presented for the all $23 \mathrm{EU}$ countries, depending on data coverage and availability.

Sources: Eurostat and LFS microdata, authors' computations. 
Figure 5: Mobility index vs. structure indicators
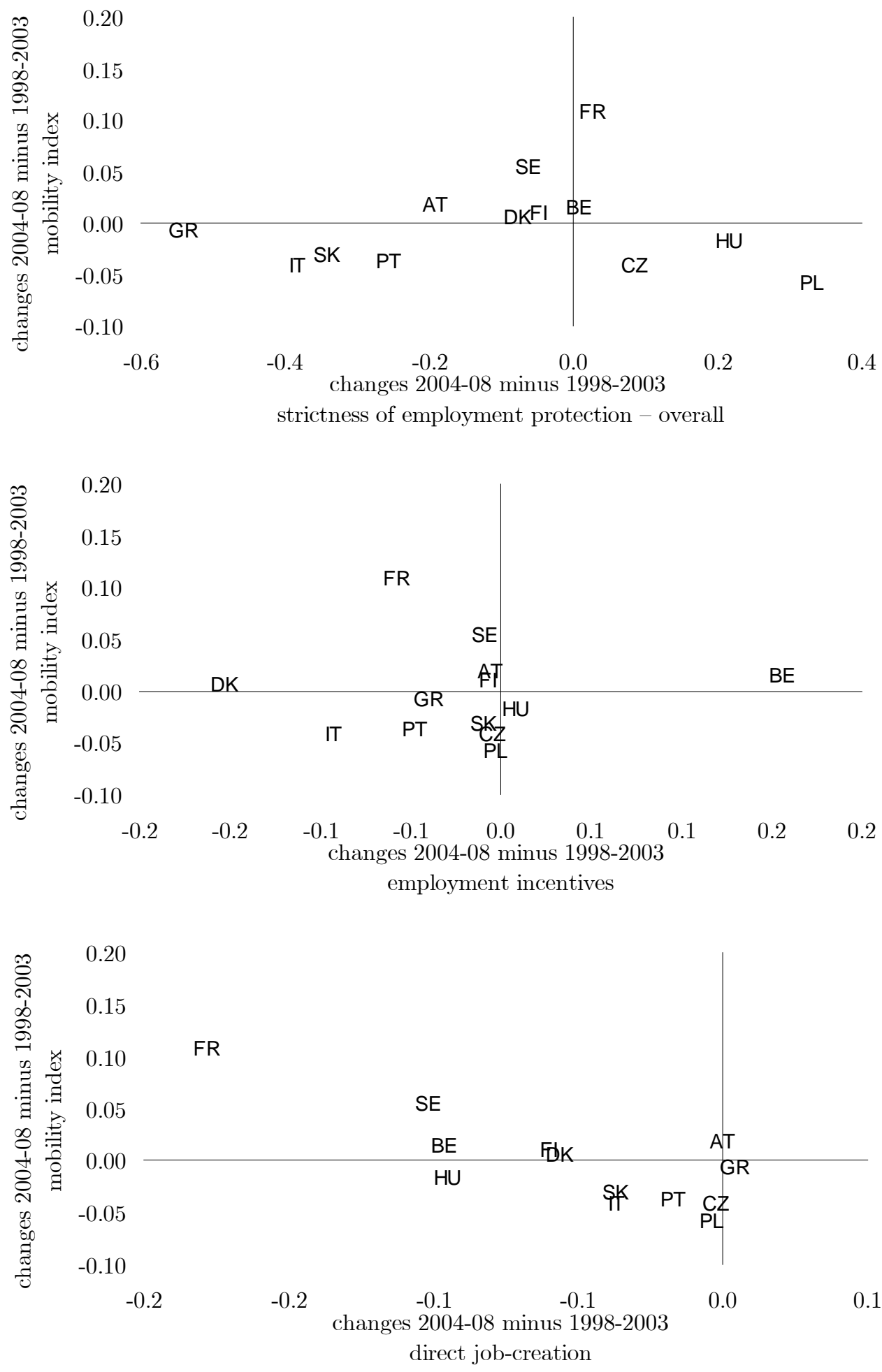
Figure 5(continued): Mobility index vs. structure indicators

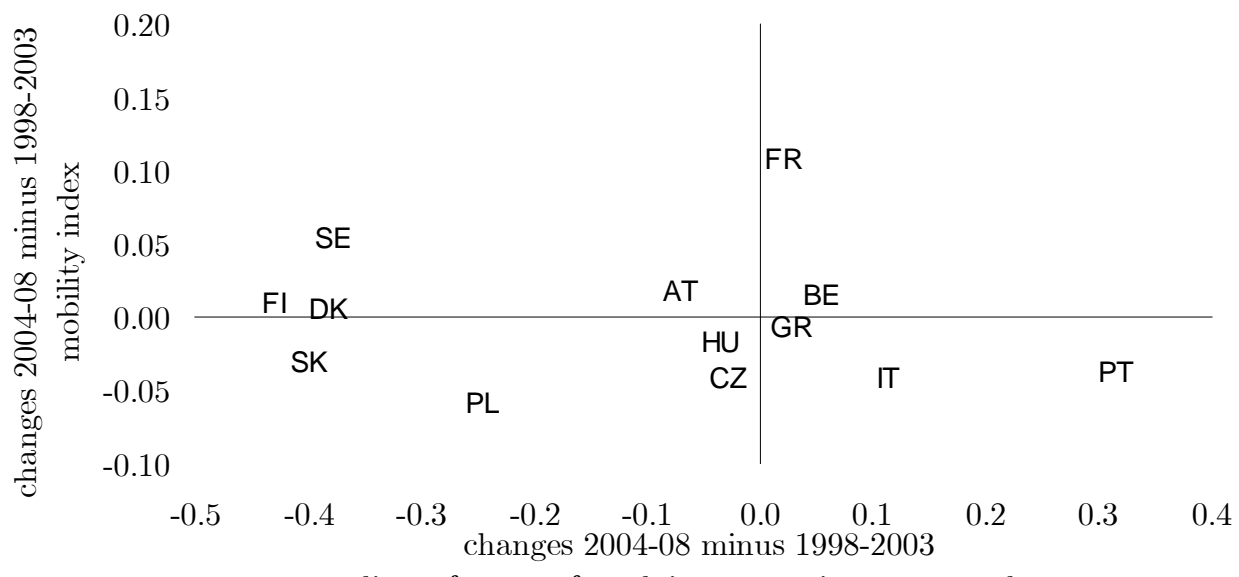

expenditure for out-of-work income maintenance and support

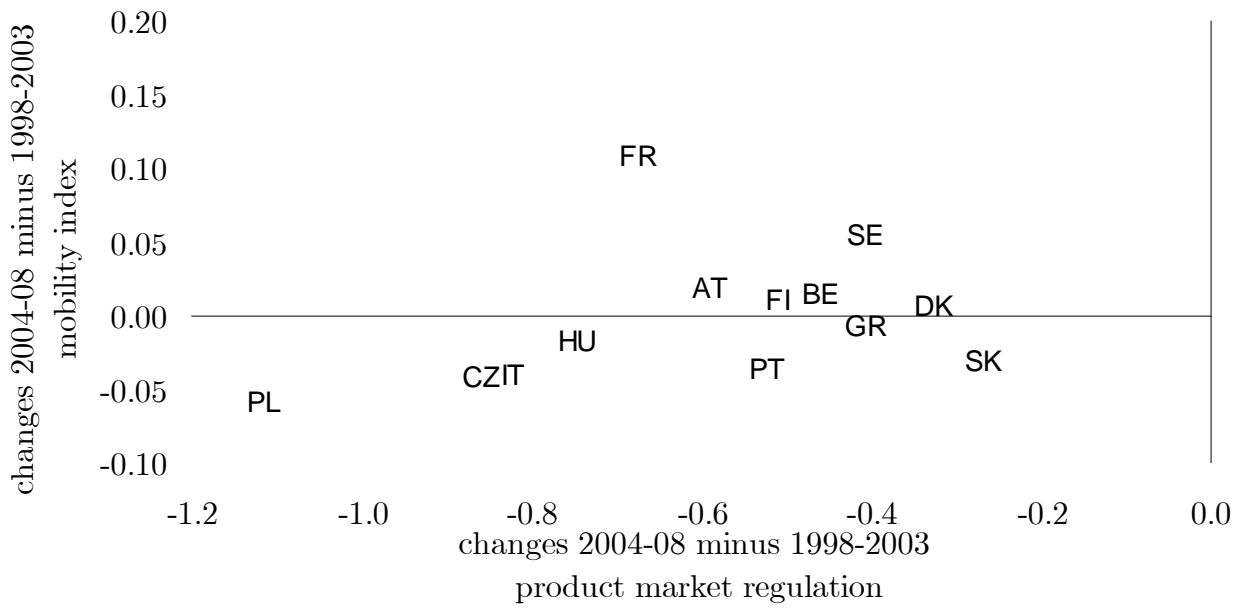

Notes: Where available, the chart refers to pooled transition probabilities results for 23 EU countries. Spain (ES), Italy (IT), France (FR), the Netherlands (NL), Belgium (BE), Austria (AT), Cyprus (CY), Finland (FI), Greece (GR), Luxemburg (LU), Portugal (PT), Slovenia (SI); Czech Republic (CZ), Estonia (EE), Latvia (LV), Lithuania (LT), Hungary (HU), Poland (PL), Romania (RO) and Slovakia (SK); Denmark (DK) and Sweden (SE). Changes for the variables on the x-axis are the difference between 2004-08 and 1998-2003 averages. The expenditure on direct-job creation and out-of work income maintenance and support are intended as a percentage of GDP.

The results are not presented for the all $23 \mathrm{EU}$ countries, depending on data coverage and availability.

Sources: OECD and LFS microdata, authors' computations. 